\title{
EDITORIAL
}

\section{Polycystic Ovary Syndrome - An Opportunity To Practice Proactive Preventive Medicine}

Polycystic ovary syndrome (PCOS) is recognized as one of the most common endocrine/metabolic disorders of women. This syndrome was first described by Stein and Leventhal in $1935^{1}$. it is the most common cause of infertility in women, frequently becomes manifest during adolescence, and is primarily characterized by ovulatory dysfunction and hyperandrogenism ${ }^{2}$.

A risk factor model analysis has calculated that patients with PCOS have a 4-fold to 7-fold higher risk of myocardial infarction in comparison with age-matched control subjects ${ }^{3}$. Insulin resistance is present in around $65-80 \%$ of women with PCOS, independent of obesity, and is further exacerbated by excess weight ${ }^{4}$. Insulin resistance has been shown to worsen reproductive and metabolic features, type 2 diabetes and cardiovascular disease (CVD) risk in PCOS $^{5}$. The prevalence of obstructive sleep apnoea is increased in obese women with PCOS. Androgen levels and insulin resistance are positively associated with obstructive sleep apnoea in PCOS. Obstructive sleep apnoea contributes to further insulin resistance ${ }^{6}$. Women with PCOS are at a higher risk of developing psychological difficulties (such as depression and/or anxiety), eating disorders and sexual and relationship dysfunction ${ }^{7}$. It has been known for many years that oligo- and amenorrhoea in the presence of premenopausal levels of estrogen can lead to endometrial hyperplasia and carcinoma ${ }^{8}$. There are moderate quality data to support the finding that women with PCOS have a 2.89-fold (95\% CI 1.52-5.48) increased risk for endometrial cancer ${ }^{9}$.

The cross sectional study of 126 infertile women with polycystic ovary syndrome attending the Infertility unit of the Department of Obstertrics and Gynaecology at Bangabandhu Sheikh Mujib Medical University revealed $47.6 \%$ of the women were overweight, $39.7 \%$ was obese, $80.2 \%$ had waist circumference $>80$ $\mathrm{cm}$.Prevalence of insulin resistance was $27.8 \%$ ,dyslipidemia $93.7 \%$ metabolic syndrome $42.9 \%$. This data warrants need to intensify the lifestyle interventions and appropriate medications to prevent the long term complications.

In view of the potential for and actual presence of numerous cardiovascular and metabolic risk factors in most women with PCOS, the role of healthcare professionals should be early recognitions of the syndrome, lifestyle intervention to ensure at least 5\% weight loss, empathic monitoring, early detection of glucose intolerance, lipid abnormality, blood pressure monitoring, measuring atherogenic markers. treatment with metformin if there is glucose intolerance, statin or fibrate, nonandrogenic OCP, Spironolactone, as need for the best outcome.

(J Bangladesh Coll Phys Surg 2021; 39: 209-210) DOI: https://doi.org/10.3329/jbcps.v39i4.55939

\section{Dr. Indrajit Prasad}

Professor \& Head, Department of Endocrinology, Dhaka Medical College

\section{References:}

1. Stein, I.F. and Leventhal, M.L. (1934) Amenorrhea Associated with Bilateral Polycystic Ovaries. American Journal of Obstetrics \& Gynecology, 29, 181-191.

2. Azziz R, Woods KS, Reyna R, Key TJ, Knochenhauer ES, Yildiz BO J Clin Endocrinol Metab. 2004;89(6):2745.

3. Dahlgren E, Janson PO, Johansson S, Lapidus L, Oden A. Polycystic ovary syndrome and risk for myocardial infarction: evaluated from a risk factor model based on a prospective population study of women. Acta Obstet Gynecol Scand. 1992;71:599-604.

4. DeUgarte CM, Bartolucci AA, Azziz R. Prevalence of insulin resistance in the polycystic ovary syndrome using the homeostasis model assessment. Fertil Steril $2005 ; 83: 1454-60$. 
5. Meyer C, McGrath BP, Teede HJ. Overweight women with polycystic ovary syndrome have evidence of subclinical cardiovascular disease. J Clin Endocrinol Metab 2005; 90:5711-6.

6. Fogel RB, Malhotra A, Pillar G, Pittman SD, Dunaif A, White DP. Increased prevalence of obstructive sleep apnea syndrome in obese women with polycystic ovary syndrome. J Clin Endocrinol Metab 2001;86:1175-80.
7. Himelein MJ, Thatcher SS. Polycystic ovary syndrome and mental health: A review. Obstet Gynecol Surv 2006;61:723-32.

8. Chamlian DL, Taylor HB. Endometrial hyperplasia in young women. Obstet Gynecol 1970;36:659-66.

9. Haoula Z, Salman M, Atiomo W. Evaluating the association between endometrial cancer and polycystic ovary syndrome. Hum Reprod 2012;27:1327-31. 